\title{
Editorial
}

\section{Chemosensors Comes of Age}

\author{
Igor L. Medintz (1)
}

Citation: Medintz, I.L Chemosensors Comes of Age. Chemosensors 2021, 9 , 22. https://doi.org/10.3390/ chemosensors 9020022

Received: 14 January 2021

Accepted: 15 January 2021

Published: 27 January 2021

Publisher's Note: MDPI stays neutral with regard to jurisdictional claims in published maps and institutional affiliations.

Copyright: (C) 2021 by the author. Licensee MDPI, Basel, Switzerland. This article is an open access article distributed under the terms and conditions of the Creative Commons Attribution (CC BY) license (https:// creativecommons.org/licenses/by/ $4.0 /)$.
Center for Bio/Molecular Science and Engineering, U.S. Naval Research Laboratory, Code 6907, 4555 Overlook Ave, SW, Washington, DC 20375, USA; Igor.medintz@nrl.navy.mil

It has now been just over eight years since I had the pleasure of introducing Chemosensors to the world [1]. Established by the Multidisciplinary Digital Publishing Institute (MDPI, Basel, Switzerland), the intent was to provide a forum that covers all aspects of the science and technology of chemical sensors as an international, scientific, peer-reviewed, open access journal, and in this regard the journal has more than amply succeeded.

I have named this editorial piece "Chemosensors Comes of Age" is to reflect the stage of growth and maturity that Chemosensors now finds itself in after just eight short years. In 2015, Chemosensors began being indexed by the Emerging Sources Citation Index (ESCI; Web of Science). Then, in 2020 the journal achieved its first official Journal Impact Factor of 3.108, which places it in 27/86 (Q2) in "Chemistry, Analytical", 13/27 (Q2) in "Electrochemistry", and 16/64 (Q1) in "Instruments \& Instrumentation" according to the InCites Journal Citation Reports (Clarivate Analytics, https://jcr.clarivate.com/). The journal also averaged $\sim 17,500$ abstract and full-text views per month over the last year. Although Chemosensors is an open access journal, our high standards mean that we also have a rejection rate of $>30 \%$ over the same time period while still striving for an almost consistent average time of $<20$ days for a first round of reviews. Moreover, in December 2020 the journal increased its publication rate from quarterly (four issues per year) to monthly (12 issues per year).

Since its inception, the journal has focused on building and supporting the sensing community. Rather than taking an approach that focuses on creating a very exclusive journal by limiting both who is published and what is included in the journal, we encouraged direct community participation in several different but important ways. First, the journal maintains an extensive Editorial Board so as to provide it with expertise in almost all areas of chemosensing. Chemosensors regularly runs Special Issues to create collections of papers on specific topics, and anyone is allowed to contact the journal and suggest a Special Issue topic or guest editor even to include themselves. These suggestions are taken very seriously by the journal's Editorial and Topics Boards, with many invitations extended. The journal also actively solicits Special Issue topics and guest editors. We maintain a Reviewer Board which is populated by our most frequent and useful reviewers, each of whom also post their position, institution, and a link. We further allow readers to register with the journal to be a reviewer, which we believe helps extend and diversify our base of expertise from which we draw potential reviewers. Editors and selected Editorial Board members are asked to review each set of reviews and to adjudicate if there are conflicting reviewer reports. Chemosensors actively supports conferences across the globe that are focused on directly related subjects and sponsors annual travel, young investigators, and best paper awards. Lastly, as a journal we have opened ourselves up to encouraging submission and publishing of many different types of manuscripts beyond the standard experimental and review formats. We encourage manuscripts on research proposals and research ideas that have not made it to an experimental stage yet, manuscripts communicating to a broader audience on research projects financed with public funds, and manuscripts on book and product reviews, along with editorials and even concept papers that are future-looking or purely theory. Additionally, announcements regarding academic activities such as conferences are published for free in the News and Announcements section of the journal. 
Chemosensors has clearly grown from its birth through infancy and into adolescence, and now it is on the cusp of adulthood. Unfortunately for me at least, the time has come when Chemosensors now demands far more to continue growing and to be successful than I can deliver to it due to the exigencies of my other professional demands. All parents must learn to let go when their children move into adulthood. As such, and in the best interests of the journal, it is with some sadness that I have decided to step down as Founding Editorin-Chief. All is not sad, however, as I am also very happy to report that Chemosensors will move on under the control of a very good set of hands. Prof. Dr. Nicole Jaffrezic-Renault from the Institute of Analytical Sciences of the University of Lyon in Villeurbanne, France, will take over as the next Editor-in-Chief of Chemosensors. She is the Emeritus Director of Research at the Centre National de la Recherche Scientifique, past president of the chemical micro sensor club (CMC2), president of the Analytical Division, a and member of the administrative council of the French Chemical Society. Her current research focuses on the conception and design of (bio)chemical sensors and their integration in microsystems. With more than 560 papers that have been cited more than 11,400 times, she is certainly one of the top scientists worldwide in this field. I could not think of a better person to be at the helm of this journal as it continues to grow. Prof. Jaffrezic-Renault will continue to be ably assisted by the journal's other editors, including Prof. Dr. James Covington (School of Engineering, University of Warwick), Prof. Dr. Franz L. Dickert (Institute of Analytical Chemistry, University of Vienna), and Dr. Michele Penza (Italian National Agency for New Technologies and Brindisi Research Center), along with myself and the journal's Advisory Board.

Where will Chemosensors go in the next decade? That is not for me to speculate too much about. What I can comment on is the continued role of and critical need for chemoand all manner of related sensors in our society. As I write this, the dangers posed by biological agents, and especially by naturally occurring agents in the form of the SARS$\mathrm{CoV}-2$ coronavirus, have fully materialized from just a conceptual threat on the horizon to the currently realized global pandemic. Along with a vaccine, overcoming this pandemic will require monitoring and detecting both its presence and its transmission [2]. There are a myriad of other sensors that are also required to support this challenge, from monitoring air flow and quality to patient immune response and the levels of drugs that are administered to them, to name but a paltry few. As a society, we must also realize that this is not a once in a lifetime event, such as the Spanish Flu of 1918 [2], but rather a foreshadowing of what is to come repeatedly in our current global civilization. There has never been a greater need for (chemo)sensors, and, just like every other technology we need to develop, it all starts with research and the dissemination and sharing of that research in a scholarly form. I look forward to reading all about new types of sensor development in this journal as it continues to grow and meet the needs of the chemosensing community.

Conflicts of Interest: The author declares no conflict of interest.

\section{References}

1. Medintz, I.L. Chemosensors-Welcome to a New Open Access Journal Intended to Cover All Aspects of Chemical Sensing. Chemosensors 2013, 1, 1-2. [CrossRef]

2. Walper, S.A.; Aragonés, G.L.; Sapsford, K.E.; Brown, C.W., III; Rowland, C.E.; Breger, J.C.; Medintz, I.L. Detecting Biothreat Agents: From Current Diagnostics to Developing Sensor Technologies. ACS Sens. 2018, 10, 1894-2024. [CrossRef] [PubMed] 